\title{
Uji Pemangsaan dan Tanggap Fungsional Predator Chysoperla carnea Stephens (Neuroptera: Crysopidae) Terhadap Phenacoccus manihoti Matile-Ferrero (Hemiptera: Pseudococcidae)
}

\author{
I WAYAN DIRGAYANA ${ }^{1}$, I WAYAN SUPARTHA ${ }^{2 *}$, DAN I NYOMAN WIJAYA ${ }^{2}$ \\ ${ }^{1}$ Program Studi Magister Pertanian Lahan Kering, Fakultas Pertanian, Universitas Udayana \\ ${ }^{2}$ Program Studi Doktor Ilmu Pertanian dan Laboratorium Pengelolaan Hama dan Penyakit \\ Terpadu (IPMLaB), Fakultas Pertanian Universitas Udayana \\ ${ }^{*}$ E-mail: yansupartha@yahoo.com
}

\begin{abstract}
Predation and Functional Response Test of Predator Chysoperla carnea Stephens (Neuroptera: Crysopidae) Against Phenacoccus manihoti MatileFerrero (Hemiptera: Pseudococcidae). This study aims to evaluate the predatory capacity of $C$. carnea by measuring the rate of searching capacity and handling-time of one prey and its functional response to the population density of $P$. manihoti. The research was conducted at the Integrated Pest Management Laboratory (IPMLab), Faculty of Agriculture, Udayana University. The study was conducted from February to May 2019. Testing of functional responses used a randomized block design with 5 treatments $(3,6,9,12,15$ nymphs-3) each of which was repeated 10 times. The results showed that the prey searchingcapacity when the population was low (3 nymphs-3) took longer (10.37 minutes), while when the population was high it took a short time (6.23 minutes). The length of time for handling one prey in the low population was 6.08 minutes, while in the high population it was 5.48 minutes. Predator $C$. carnea has a tpe- 2 functional response to an increase in the population of P. manihoti nymphs with the equation $\mathrm{Y}=4.32 \mathrm{x} / 1+1.973 \mathrm{x}\left(\mathrm{R}^{2}=0.980\right)$. The rate of predation increases sharply when the population of low increases, and decreases when the increase of prey population increases. C. carnea has the potential to be developed as a control agent for P. manihoti.
\end{abstract}

Keywords: Predation, functional response, C. carnea, P. manihoti, cassava

\section{PENDAHULUAN}

Phenacoccos manihoti Matile-Ferrero

(Hemiptera: Pseudococcidae) merupakan salah satu hama penting yang menyerang tanaman ubi kayu di Indonesia. P. manihoti mulai menjadi perhatian dunia sejak hama 


\section{WAYAN DIRGAYANA et al. Uji Pemangsaan dan Tanggap Fungsional Predator...}

tersebut terbawa masuk secara tidak sengaja ke Afrika pada tahun 1970 (Nwanze et al., 1979) dan ke Asia pada tahun 2009 (Parsa et al., 2012). Pada tahun 2910 hama tersebut pertama kali ditemukan di Bogor, Indonesia (Muniappan et al., 2009). Akibat serangan hama tersebut menyebabkan kehilangan hasil panen sekitar $82 \%$ di Afrika (Nwanze, 1982) dan 40-50\% di Asia (Wardani, 2015)

Sampai saat ini upaya yang dilakukan petani dalam menanggulangi kehilangan hasil akibat serangan $P$. manihoti masih bertumpu pada penggunaan insektisida yang dampaknya sangat berbahaya bagi lingkungan dan kesehatan manusia. Upaya pengendalian menggunakan agens hayati dapat mengurangi penggunaan insektisida. Agens hayati yang banyak digunakan untuk mengendalikan hama kutu putih adalah serangga predator dan parasitoid. Purnomo (2010) telah mengidentifikasi beberapa jenis predator hama kutu putih $P$. manihoti yaitu kumbang Crysoperla Carnea, Exochomus, Hyperaspis, Scymnus sp., Coccinella transversalis dan Cryptolaemus montrouzieri. Karakteristik serangga predator tersebut adalah membunuh dan memakan langsung mangsanya lebih dari satu mangsa per hari. Pemangsaan tersebut dilakukan sampai stadia dewasa. Sejauh ini belum tersedia informasi yang yang rinci dan memadai mengenai peranan dan keefektifan $C$. carnea sebagai agens pengendalian hayati $P$. manihoti.

Penelitian bertujuan untuk mengevaluasi kapasitas pencarian mangsa dan waktu penanganan satu mangsa dan tanggap fungsional predator $C$. carnea terhadap kepadatan populasi $P$. manihoti sebagai dasar untuk menilai keefektifannya dalam pengendalian hayati $P$. manihoti pada tanaman ubi kayu.

\section{METODE PENELITIAN}

Penelitian dilakukan mulai bulan Februari 2019 sampai dengan Mei 2019. Lokasi Penelitian dilakukan di Laboratorium Intergrated Pest Management (IPMLab), Fakultas Pertanian, Universitas Udayana.

\section{Pemeliharaan Kutu Putih $P$. manihoti dan Predator C. carnea}

Tanaman ubi kayu yang digunakan sebagai tanaman inang diperoleh dari pertanaman singkong milik petani Desa Sekaan, Kecamatan Kintamani Bangli. Tanaman tersebut digunakan untuk membiakkan $P$. manihoti. Stek singkong berukuran panjang sekitar $15 \mathrm{~cm}$ ditanam dengan posisi tegak ke dalam polybag $(t=12$ $\mathrm{cm}, \mathrm{d}=8 \mathrm{~cm}$ ) yang berisi tanah. Bibit 
singkong dibiarkan tumbuh selama 3 minggu sampai muncul daun. Kemudian diinfestasi dengan 2 ekor kutu putih $P$. manihoti per stek tanaman

Sementara itu pembiakan telur dan larva predator $C$. carnea yang diperoleh dari pertanaman ubi kayu terserang kutu putih di Desa Temesi, Kecamatan Gianyar Kabupaten Gianyar menggunakan kurungan plastik berukuran diameter $=30$ $\mathrm{cm}$ dan tinggi $35 \mathrm{~cm}$ yang telah berisi tanaman ubi kayu dan hama kutu putih $P$. manihoti dengan jumlah 200 ekor. Pada bagian depan kurungan diberi jendela dan ditutup dengan kain kasa.

\section{Perilaku Pemangsaan Predator terhadap Stadia $P$. manihoti}

Kepadatan masing-masing mangsa yang diuji adalah 3, 6, 9, 12 dan 15 ekor mangsa (batas minimum dan maksimum pemangsaan). Kepadatan populasi sebanyak 3 ekor mewakili kepadatan rendah, sedangkan kepadatan populasi sebanyak 15 ekor mewakili kepadatan tinggi dalam tanaman ubi kayu. Setiap perlakuan diulang sebanyak 10 kali. Inokulasikan larva predator instar-3 C. carnea yang telah dilaparkan selama 24 jam pada masing- masing perlakuan yang telah dipersiapkan. Setelah itu dilakukan pengamatan terhadap perilaku pemangsaan predator sesaat setelah inokulasi dilakukan yaitu mulai pukul 06.00- 18.00 WITA.

Peubah yang diamati adalah (1) lama pencarian mangsa meliputi (a) lama mencari mangsa pertama dengan cara menghitung waktu yang diperlukan untuk mendapatkan mangsa pertama sejak predator dilepaskan. (b)selang waktu pencarian mangsa kedua setelah selesai memakan mangsa pertama, dan demikian seterusnya untuk pencarian mangsa selanjutnya. (2) Lama penanganan satu mangsa yaitu waktu yang dibutuhkan untuk menangani satu mangsa. Lama penanganan satu mangsa diperoleh dari hasil penghitungan waktu sejak predator menangkap mangsa sampai predator menghabiskan mangsa tersebut. Tanggap fungsional adalah kemampuan individu predator untuk melakukan pemangsaan terhadap peningkatan kepadatan populasi mangsa. Laju pemangsaan $C$. carnea terhadap kepadatan mangsa tersebut dilakukan dengan menggunakan rumus Holling (1959) sebagai berikut: 


\section{WAYAN DIRGAYANA et al. Uji Pemangsaan dan Tanggap Fungsional Predator...}

$$
\mathrm{Na}=\frac{\mathrm{aTN}}{1+\mathrm{aThN}}
$$

Keterangan:

$\mathrm{Na}=$ jumlah mangsa yang dimangsa

a $\quad$ laju pemangsaan

$\mathrm{T}=$ lama pemangsaan (12 jam)

$\mathrm{N}=$ kerapatan mangsa

Th = waktu yang dibutuhkan predator untuk menangani satu mangsa

Penentuan tipe tanggap fungsional dilakukan dengan menggunakan analisis regresi yaitu dengan menghitung jumlah mangsa yang dikonsumsi $(\mathrm{Ne})$ dan dibandingkan dengan jumlah mangsa yang dipaparkan (No). Data pemangsaan dianalisis menggunakan regresi linear, eksponensial, dan logaritmik. Penentuan persamaan regresi terhadap tipe tanggap predator terhadap kepadatan mangsanya diukur dari besaran nilai $\mathrm{R}^{2}$ dan simpangan baku persamaan tersebut. Besaran nilai $\mathrm{R}^{2}$ tertinggi atau mendekati 1 dan nilai simpangan baku terendah digunakan sebagai dasar penentuan persamaan yang dipilih dan penentu dari tipe tanggap fungsional (Jones et al., 2003).

\section{HASIL DAN PEMBAHASAN}

\section{Perilaku Pemangsaan}

Hasil pengamatan dilabolatorium menunjukkan bahwa Perilaku predator dalam proses pencarian mangsa, diawali oleh proses pengenalan habitat mangsa, proses pencarian mangsa dengan mengelilingi habitat (cawan petri) mangsa untuk beradaptasi dengan lingkungan di sekitarnya. Pada proses pencarian mangsa tersebut, predator Gerakan yang sangat aktif dan gerakan yang agresif pada saat menemukan mangsa dan mengejar mangsanya. Kejadian tersebut ditunjukkan pada waktu predator menemukan mangsa pertamanya.

Waktu yang dibutuhkan oleh larva instar-3 predator C. canea untuk menemukan mangsa pertamanya, baik pada kepadatan tinggi atau rendah disajikan pada Tabel 1. Predator $C$. carnea membutuhkan waktu 10,37 menit menemukan mangsa pertamanya pada kepadatan mangsa rendah (3 ekor) dan 6,23 menit pada kepadatan mangsa tinggi (15 ekor). Predator membutuhkan waktu lebih lama mencari mamgsa pertama pada kepadatan rendah dibandingkan pada kepadatan tinggi karena 
pencarian mangsa pada kepadatan rendah (tiga individu mangsa), predator perlu melakukan orientasi pencarian mangsa secara berulang sampai menemukan mangsa. Berbeda dengan proses pencarian mangsa pada kepadatan tinggi yang berjumlah 15 ekor, keberadaan mangsa lebih mudah ditemukan karena bergerombol sehingga dalam waktu singkat dapat menemukan mangsa. Hasil penelitian ini memperkuat hasil penelitan Pratiwi et al. (2018) bahwa pencarian mangsa pada saat populasi terendah membutuhkan waktu yang lama karerna sebagian besar waktunya digunakan untuk mencari mangsa sehingga jumlah mangsa yang tertangkap lebih rendah per satuan waktu.

Predator membutuhkan waktu lebih singkat untuk menemukan mangsanya pada saat kepadatan tinggi, karena jumlah mangsa yang banyak memudahkan predator untuk mencari dan menemukan mangsa pertama maupun mangsa selanjutnya. Supartha \& Susila (2001) menjelaskan bahwa pada saat kerapatan populasi mangsa tinggi, predator Curinus coeruleus Mulsant (Coleoptera: Coccinelidae) lebih mudah menemukan mangsanya, karena perilaku hidup mangsanya bergerombol sehingga mangsa relatif sulit menghindar dari serangan predator.

Tabel 1. Rata-rata lama pencarian dan penanganan mangsa $P$. manihoti oleh predator $C$. carnea

\begin{tabular}{|c|c|c|}
\hline Prilaku Pemangsaan Predator Pada $P$. manihoti & $\begin{array}{l}\text { Kepadatan } \\
\text { rendah }\end{array}$ & $\begin{array}{l}\text { Kepadatan } \\
\text { tinggi }\end{array}$ \\
\hline Larva instar-3 C. carnea & \multicolumn{2}{|c|}{$\ldots$ menit ... } \\
\hline Lama pencarian mangsa pertama (menit) & 10,37 & 6,23 \\
\hline Lama pencarian mangsa selanjutnya (menit) & 7,38 & 5,42 \\
\hline Lama penanganan satu mangsa pertama (menit) & 6,08 & 5,48 \\
\hline Lama Penanganan satu mangsa selanjutnya (menit) & 6,21 & 5,76 \\
\hline
\end{tabular}

Proses pencarian mangsa selanjutnya membutuhkan waktu lebih singkat, daripada waktu pencarian mangsa pertama. Predator langsung mencari mangsa selanjutnya setelah selesai menangani mangsa pertamanya. Waktu yang dibutuhkan oleh predator $C$. carnea untuk menemukan mangsa selanjutnya adalah 7,38 menit (Tabel 1).

Sementara rata-rata lama penanganan satu mangsa pertama oleh larva $C$. carnea membutuhkan waktu (6,08 menit). Lama 


\section{WAYAN DIRGAYANA et al. Uji Pemangsaan dan Tanggap Fungsional Predator...}

waktu penanganan tersebut terkait dengan tingkat kerlaparan dan kerakusan predator tersebut.

Predator yang diuji adalah dalam keadaan lapar karena sudah dipuasakan selama 24 jam sebelum dilakukan pengujian. Predator dalam keadaan lapar biasanya sangat rakus dan lebih agresif mencari dan menangani mangsanya. Keadaan lapar bagi predator merupakan prasyarat awal untuk mencari, menemukan dan melakukan pemangsaan terhadap mangsanya guna memenuhi kebutuhan bagi kelangsungan dari hidup dan perkembangbiakannya (Wahyuningsih, 2018).

\section{Tanggap Fungsional}

Hasil analisis regresi menunjukkan bahwa predator $C$. carnea mempunyai tanggap terhadap kepadatan populasi $P$. manihoti. Laju pemangsaan predator semakin meningkat dengan meningkatnya kerapatan populasi mangsa (Tabel 2). Berdasarkan hasil analisis tiga persamaan regresi yang diuji untuk memilih tipe tanggap fungsional yang dimiliki oleh predator tersebut menunjukkan bahwa ada perbedaan nilai $\mathrm{R}^{2}$ dari ketiga bentuk persamaan regresi yang diuji. Nilai $R^{2}$ menentukan tingkat keeratan dari masingmasing persamaan terhadap tipe tanggap fungsional yang dimiliki oleh predator. Predator C. carnea memiliki tanggap fungsional tipe-2 (logaritmik) karena nilai $\mathrm{R}^{2}(0,980)$ nya paling tinggi dibandingkan dengan nilai $\mathrm{R}^{2}(0,930)$ persamaan tipe-1 dan nilai $\mathrm{R}^{2}(0,860)$ persamaan tipe-3 (Gambar 1). Tanggap fungsional tipe-2 menggambarkan bahwa jumlah mangsa termangsa oleh individu predator meningkat sejalan dengan tingkat kepadatan mangsa. Laju pemangsaan pada fase awal meningkat tajam, kemudian pada tingkat kepadatan tertentu lajunya mulai mengendur (Gambar 1). Menurut Supartha (1991) predator yang memiliki tanggap fungsional tipe-2 mempunyai laju pemangsaan semakin meningkat dan kemudian mengendur mulai pada kerapatan mangsa tertentu. Mortalitas mangsa maksimal terjadi pada kerapatan mangsa yang rendah. Berdasarkan tanggap fungsional tipe-2 yang dimilliki oleh predator $C$. carnea menggambarkan bahwa predator tersebut potensial untuk pengaturan populasi mangsanya di alam. 
Tabel 2. Respon fungsional C. montouzieri terhadap beberapa tingkat kerapatan mangsa $P$. Manihoti

\begin{tabular}{lll}
\hline \multicolumn{1}{c}{ Perlakuan } & \multicolumn{2}{l}{ Larva Instar-3 Predator } \\
\cline { 2 - 3 } & C. carnea & \\
\hline Total waktu yang tersedia $(\mathrm{T})$ & 12 jam & \\
Laju penanganan mangsa (a) & $0,36 \mathrm{Menit}$ & \\
Waktu untuk 1 mangsa (Th) & 5,48 Menit & \\
Persamaan Regresi & Y=4,32X/1+1,973X & \\
Koefisien Korelasi $\left(\mathrm{R}^{2}\right)$ & Linier : $0,930-$ & Tipe I \\
& Logaritmik : $0,980-$ & Tipe II \\
& Eksponensial : $0,860-$ & Tipe-III \\
\hline
\end{tabular}

Hasil analisis tersebut diperkuat oleh hasil pengamatan yang dilakukan oleh predator pada proses pencarian dan penanganan mangsa langsung pada kepadatan rendah maupun tinggi. Predator memerlukan waktu relatif lama untuk menemukan mangsa pada kerapatan populasi rendah dibandingkan pada kerapatan populasi tinggi. Waktu yang tersedia tidak dapat digunakan secara efektif oleh predator dalam menemukan mangsa. Pada kepadatan tinggi predator lebih mudah menemukan mangsa karena interval penemuan mangsa lebih singkat.
Keadaan tersebut dapat menggambarkan kapasitas dan potensi predator dalam mengendalikan mangsanya. Sebagaimana disebeutkan sebelumnya bahwa $C$. cranea yang memiliki tanggap fungsional tipe-2 mempunyai potensi untuk dikembangkan sebagai agens hayati $P$. manihotii. Menurut Supartha \& Susila (2001) musuh alami yang mempunyai tanggap total yaitu tasnggap fungsional dan tanggap numerik yang meningkat terhadap peningkatan mangsa berarti predator dapat berperan untuk menekan populasi mangsa di alam.

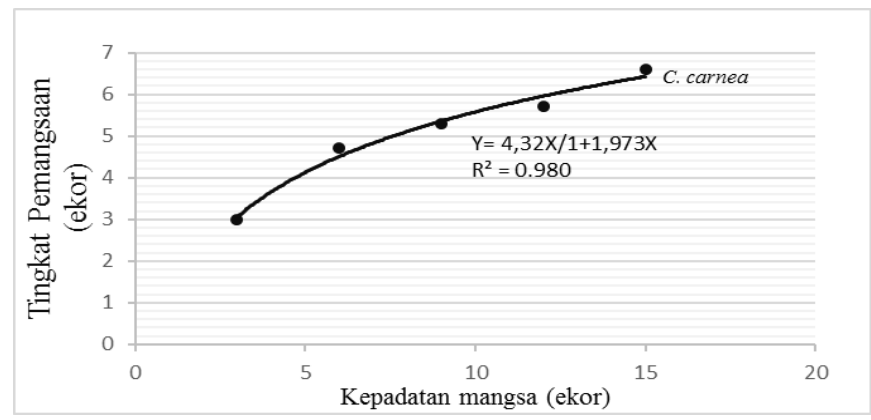

Gambar 1. Tanggap fungsional predator $C$. carnea terhadap kepadatan populasi kutu putih $P$. manihoti 


\section{WAYAN DIRGAYANA et al. Uji Pemangsaan dan Tanggap Fungsional Predator...}

Tanggap fungsional larva instar-3 predator C. carnea terhadap nimfa instar-3 kutu $P$. manihoti termasuk tipe-2 yaitu semakin meningkat jumlah mangsa yang tersedia maka kemampuan pemangsaannya semakin meningkat (Gambar 1). Kemampuan memangsa tersebut dipengaruhi oleh waktu yang tersedia bagi predator untuk mencari dan memakan mangsa. Pada saat populasi mangsa rendah, biasanya predator sulit menemukan mangsanya. Sebagian besar waktu yang tersedia digunakan predator untuk mencari mangsa sehingga jumlah mangsa yang tertangkap rendah per satuan waktu. Pemanfaatan waktu semakin efisien pada saat populasi mangsa tertinggi, karena sebagian besar waktu digunakan oleh predator untuk memakan mangsa atau hanya sebagian kecil waktu yang digunakan untuk mencari mangsa (Supartha, 1991; Susilo, 2007; Wahyuni et al., 2017).

\section{SIMPULAN}

Predator C. carnea mempunyai lanju pemangsaan yang semakin meningkat dengan meningkatkan kerapatan populasi mangsa, C. carnea mempunyai potensi untuyk dikembangkan sebagai agens pengendalian $P$. manihoti. Kapasitas pencarian mangsa predator $C$. carnea lambat pada saat populasi mangsa rendah (3 ekor)(10,37 menit), dan cepat pada saat populasi mangsa tinggi (15ekor) (6,23 menit). Waktu penanganan satu mangsa juga lama pada saat populasi mangsa rendah (3ekor) (6,08 menit), dan cepat pada saat populasi mangsa tinggi (15ekor) $(5,48$ menit). Predator $C$. carnea memiliki tanggap fungsional tipe-2 (logaritmik) dengan persamaan $\mathrm{Y}=4,32 \mathrm{X} / 1+1,973 \mathrm{X}\left(\mathrm{R}^{2}\right.$ $=0.980)$. Laju pemangsaan predator secara individual meningkat tajam pada fase awal, kemudian pada tingkat kepadatan tertentu lajunya semakin mengendur.

\section{UCAPAN TERIMA KASIH}

Penulis mengucapkan terimakasih kepada Prof. Dr. Ir. I Wayan Supartha, M.S Ketua tim Hibah Grup Riset Fakultas Pertanian, Universitas Udayana dengan nomor kontrak: 1687/UN.14.2.6.11/LT/ 2019 atas bantuan pendanaan dalam penelitian ini. Penulis berterimakasih kepada Dicky Marsadi, I Kadek Wisma Yudha dan I Wayan Eka Karya atas bantuannya dalam koleksi dan analisis data.

\section{DAFTAR PUSTAKA}

Holling, C. S. (1959). Some Characteristics of Simple Types of Predation and Parasitism. The Canadian Entomologist, $\quad 91(7), \quad$ 385-398. 
https://doi.org/10.4039/Ent91385-7

Jones, D. B., Giles, K. L., Berberet, R. C., Royer, T. A., Elliott, N. C., \& Payton, M. E. (2003). Functional Responses of an Introduced Parasitoid and an Indigenous Parasitoid on Greenbug at Four Temperatures. Environmental Entomology, 32(3), 425-432. https://doi.org/10.1603/0046-225X32.3.425

Muniappan, R., Shepard, B. M., Watson, G. W., Carner, G. R., Rauf, A., Sartiami, D., Hidayat, P., Afun, J. V. K., Goergen, G., \& Rahman, A. K. M. Z. (2009). New Records of Invasive Insects (Hemiptera: Sternorrhyncha) in Southeast Asia and West Africa. Journal of Agricultural and Urban Entomology, 26(4), 167-174. https://doi.org/10.3954/1523-547526.4.167

Nwanze, K. F. (1982). Relationships between cassava root yields and crop infestations by the mealybug, Phenacoccus manihoti. Tropical Pest Management, 28(1), 27-32. https://doi.org/10.1080/09670878209 370669

Nwanze, K. F., Leuschner, K., \& Ezumah, H. C. (1979). The Cassava Mealybug, Phenacoccus sp. in the Republic of Zaire. PANS, 25(2), 125-130. https://doi.org/10.1080/09670877909 411685

Parsa, S., Kondo, T., \& Winotai, A. (2012). The Cassava Mealybug (Phenacoccus manihoti) in Asia: First Records, Potential Distribution, and an Identification Key. PLoS ONE, 7(10), 47675.

https://doi.org/10.1371/journal.pone.0 047675

Pratiwi, N. P. E., Supartha, I. W., \& Yuliadhi, K. A. (2018). Aktivitas Penerbangan dan Perkembangan Populasi Thrips parvispinus Karny
(Thysanoptera: Thripidae) pada Tanaman Cabai Besar (Capsicum annuum L.). Agrotrop: Journal on Agriculture Science, 8(1), 29-37.

Purnomo, H. (2010). Pengantar Pengendalian Hayati. CV Andi Offset (Penerbit ANDI).

Supartha, I. W. (1991). Perilaku dan Parasitisme Lysiphlebus testacipes (Cresson) (Hymenoptera: Apidiidae) Terhadap Kutu Daun, Aphis craccivera Kock (Homoptera: aphididae) pada Empat Jenis Tanaman Kacang-Kacangan. Institut Pertanian Bogor.

Supartha, I. W., \& Susila, I. W. (2001). Uji Pemangsaan Curinus coeruleus Mulsant (Coeloptera: Coccinellidae) pada Diaphorina citri Kuw. (Homoptera: Psyllidae) dan Heteropsylla cubana Crawford (Homoptera: Psyllidae). Agritrop, Journal on Agricultural Sciences, 20(1), 5-9.

Susilo, F. X. (2007). Pengendalian Hayati dengan Memberdayakan Musuh Alami. Graha Ilmu.

Wahyuni, S., Supartha, I. W., \& Ubaidillah, R. (2017). Functional Response of Opius chromatomyiae Belokobylskij \& Wharthon (Hymenoptera: Eulopidae) Parasitoid on Leaf Miner, Liriomyza Sativae Blanchard (Diptera: Agromyzidae). 5(1), 17-21.

Wahyuningsih, E. (2018). Biologi, Neraca Hayati dan Pemangsaan Cryptolaemus montrouzieri (Mulsant) (Coleoptera: Coccinellidae) pada Paracoccus marginatus. Institut Pertanian Bogor.

Wardani, N. (2015). Kutu Putih Ubi Kayu Phenacoccus manihoti MatileFerrero (Hemiptera: Pseudococcidae), Hama Invasif Baru di Indonesia. Institut Pertanian Bogor. 